\title{
Downward trends in childhood obesity after 12-year school- and community-based programmes
}

\author{
M. Romon ${ }^{1}$, A. Lommez ${ }^{2}$, M. Tafflet ${ }^{3}$, A. Basdevant ${ }^{4}$, J. M. Oppert ${ }^{4}$, J. L. Bresson ${ }^{5}$, \\ P. Ducimetiere ${ }^{3}$, M. A. Charles ${ }^{3}$ and J. M. Borys ${ }^{2}$ \\ ${ }^{1}$ Lille 2 University Hospital Service de Nutrition, Lille, France, ${ }^{2}$ The Fleurbaix-Laventie Ville Santé Association, \\ Laventie, France, ${ }^{3}$ INSERM Unit 780, Villejuif, France, ${ }^{4}$ Université Pierre et Marie Curie-Paris 6, Paris, \\ France and ${ }^{5}$ Hôpital des Enfants Malades, Paris, France
}

There is an urgent need for sustainable programmes that reduce childhood obesity. In two towns in northern France (Fleurbaix and Laventie; FL) a school-based nutrition information programme was initiated in 1992 and was followed by a number of community-based interventions ${ }^{(1-3)}$. The opportunity was taken to measure the outcomes in terms of childhood obesity and overweight over the next 12 years.

The design was a repeated cross-sectional school-based survey. For the school years beginning in 1992, 2000, 2002, 2003 and 2004, the height and weight of all 7-12-year-old children attending school in FL were measured. In 2004 the same assessments were made in two towns (CT) with similar socio-economic characteristics but no intervention.

The OR for the age-adjusted prevalence of overweight were calculated using generalized estimation equations. Comparisons between FL and CT were performed using a multivariate linear regression model, adjusted for height and age, for weight and BMI and with Pearson $\chi^{2}$ tests for overweight prevalence.

The prevalence of childhood overweight in FL was $11.4 \%$ in 1992 and $8.8 \%$ in 2004 (NS). Using the 2002 school year as reference the age-adjusted OR for overweight in FL was significantly lower in $2003(0.65)$ and $2004(0.69)$ for girls only $(P=0.01)$. The same trend was observed in boys ( 0.82 and 0.72 respectively). For the 2004 school year the overweight prevalence was significantly lower in FL $(8.8 \%)$ than in CT $(17.8 \% ; P<0.0001)$.

At the community level it is possible to reverse trends towards increasing overweight. The data suggest that interventions targeting a variety of population groups can have synergistic effects over a long period of time.

1. Lafay L, Vray M, Boute D \& Basdevant A (1998) Rev Epidemiol Sante Publique 46, $263-275$.

2. Lafay L, Mennen L, Basdevant A, Charles MA, Borys JM, Eschwège E \& Romon M for the FLVS Study Group (2000) Int J Obes 24, 1500-1506.

3. Heude B, Lafay L, Borys JM, Thibult N, Lommez A, Romon M, Ducimetiere P \& Charles M (2003) Diabetes Metab 29, 235-240. 